\title{
Análises de Crescimento Econômico e Bem-Estar de Políticas de Privatização
}

\section{Economic Growth and Welfare Analysis of Privatization Policies}

\author{
Francisco Germano Carvalho Lucio ${ }^{\mathrm{a}}$ \\ Arley Rodrigues Bezerra ${ }^{\mathrm{b}}$ \\ Ricardo Antônio de Castro Pereira ${ }^{\mathrm{c}}$
}

Resumo: Este estudo visa analisar os efeitos sobre os agregados macroeconômicos e o bem-estar de políticas de privatização das empresas estatais. As políticas de privatização são simuladas tanto de formas isoladas quanto relacionadas a políticas de redução de ineficiência do setor público e de alíquotas tributárias e consideram cenários com destinações das receitas geradas pela privatização para infraestrutura pública e para reduzir a dívida pública. Utiliza-se um modelo de equilíbrio geral computável calibrado para a economia brasileira, considerando o cenário fiscal vigente da Emenda Constitucional 95/2016 (Teto de Gastos). Observa-se que as políticas de privatização isoladas, ainda que apresentem resultados pouco expressivos como ganhos de bem-estar de aproximadamente $0,5 \%$, podem gerar crescimento no investimento de $5 \%$. As políticas combinadas com redução da carga tributária apresentam melhores resultados nos agregados macroeconômicos, principalmente em relação ao investimento e ao produto. Por outro lado, as políticas de privatização combinadas com redução de ineficiência podem alcançar maiores ganhos de bem-estar. Mostra-se, portanto, os benefícios potenciais de políticas de privatização das empresas estatais, sobretudo quando combinadas com outras políticas.

Palavras-chave: privatização; ineficiência; carga tributária; crescimento econômico.

\begin{abstract}
This paper aims to analyze the effects of privatization policies of state-owned companies on the macroeconomic aggregates and welfare. These policies are simulated using both plain privatization policies and combined with policies of reduction of the public sector inefficiency and tax rates. It uses a computable general equilibrium model calibrated for the Brazilian economy, considering the setup of the current fiscal budget, defined by the Constitutional Amendment 95/2016. It was observed that plain privatization policies, even if they show less expressive results such as welfare gains of approximately $0.5 \%$, they might increase the investments by $5 \%$. Policies involving a

a Universidade Federal do Cariri (UFCA), Centro de Ciências Sociais Aplicadas (CCSA). Juazeiro do Norte, Ceará, Brasil.

b Universidade Federal Rural de Pernambuco (UFRPE), Unidade Acadêmica de Serra Talhada (UAST). Serra Talhada, Pernambuco, Brasil.

c Universidade Federal do Ceará (UFC), Programa de Pós-Graduação em Economia (CAEN/UFC). Fortaleza, Ceará, Brasil.
\end{abstract}


reduction in the tax burden would present better results in the macroeconomic aggregates, especially in terms of investment and GDP. On the other hand, the privatization policies combined with a reduction of inefficiency would achieve better results in terms of welfare gains. Therefore, the potential benefits of privatization policies were shown, especially when they are combined with other policies.

Keywords: privatization; inefficiency; tax burden; economic growth.

JEL Classification: C68; H20; H30; O40.

\section{Introdução}

Os recentes resultados no cenário econômico brasileiro tais como déficits primários em sucessivos anos e aumento da dívida pública e do desemprego indicam que o Brasil enfrenta uma crise fiscal e econômica. Desde o ano de 2008, o Brasil passou a apresentar superávits primários declinantes de tal forma a tornarem-se déficits primários a partir de 2014, culminando em um déficit de 2,2\% do PIB em 2017. Neste mesmo ano, a dívida líquida do setor público (DLSP) atingiu 47,4\% do PIB, sendo a dívida bruta referente a $71 \%$ do PIB. Entre fevereiro e abril de 2017, o número de pessoas à procura de emprego atingiu 14 milhões, equivalente a uma taxa de desocupação de 13,6\%.

Diante desse cenário, em 2016 aprovou-se a Emenda Constitucional (EC) 95/2016, a PEC do Teto de Gastos, visando conter a evolução da relação DLSP/ PIB e reduzir a instabilidade da economia. Apesar da tímida e recente melhora de alguns resultados macroeconômicos, a crise fiscal e econômica no país ainda persiste. Assim, vê-se a urgência na adoção de reformas e implementação de políticas que gerem maior eficiência e produtividade na economia a fim de fomentar as condições necessárias para a reversão desse cenário e a recondução da economia ao crescimento econômico.

Em ambientes de ajuste fiscal, muito se questiona os gastos e investimentos nas empresas estatais. Dessa forma, uma política cogitada é a implementação de um processo de privatização das estatais. Visando reduzir a dívida pública, na década de 1990 o Brasil adotou um processo de privatização de uma pequena parcela de seus ativos, sobretudo das empresas estatais que geravam prejuízos ou lucros insignificantes em períodos intermitentes.

Não há consenso na literatura que associa privatização a crescimento econômico. Assim, este trabalho analisa os possíveis efeitos no crescimento econômico e no nível de bem-estar agregado de políticas de privatização das empresas estatais no Brasil. Adicionalmente, considera a importância de tratar o setor público como detentor inerente de certo grau de ineficiência. Dessa forma, este estudo utiliza um mo- 
delo de equilíbrio geral dinâmico computável calibrado para a economia brasileira, modelando o setor público como ineficiente no desenvolvimento de suas atividades.

Existe, contudo, a possibilidade de que uma política de privatização não seja suficiente para garantir maior eficiência em níveis agregados necessários ao processo de retomada do crescimento, sobretudo se implementada de maneira isolada. Assim, as políticas propostas neste trabalho conjugam a privatização a outras políticas, a saber, redução nos níveis de ineficiência do setor público e na carga tributária.

No intuito de aproximar o modelo utilizado com a realidade do governo brasileiro, todos os cenários consideram um ajuste fiscal similar ao gerado pela EC 95/2016, no qual os gastos do governo permanecerão fixos por 10 anos, período mínimo de vigência da EC 95/2016. Além disso, uma vez que um dos objetivos da EC 95/2016 é conter o aumento da dívida pública brasileira, as políticas terão destinações dos recursos provenientes das privatizações para o abatimento da dívida pública. Ainda, consideram-se cenários alternativos com tais recursos sendo destinados para investimento em infraestrutura pública.

O presente trabalho é composto por seis seções, incluindo esta introdução: a segunda discorre sobre a literatura acerca dos temas abordados; a terceira especifica os componentes do modelo utilizado e define o equilíbrio de estado estacionário; quarta versa sobre a calibração dos parâmetros; a quinta define a forma utilizada para auferir a medida de bem-estar e descreve as simulações de políticas e os respectivos resultados; e, por fim, a última conclui com algumas considerações finais.

\section{Referencial Teórico}

A literatura acerca de privatização e crescimento econômico tem focado bastante em economias em desenvolvimento. Plane (1997), utilizando uma amostra de 35 países em desenvolvimento no período 1988-1992, verifica a importância da política de privatização para impulsionar o crescimento econômico, sobretudo se a privatização ocorre na indústria ou na infraestrutura. Adicionalmente, aponta a importância da política macroeconômica interna no processo de crescimento. Analisando o período de 1988 a 2008, Breen e Doyle (2013) estimam os principais determinantes da privatização em 77 países, também em desenvolvimento. Apontam que a decisão inicial de privatizar é impulsionada principalmente por fatores exógenos, enquanto a extensão e a escala de privatização são moldadas por uma variedade de condições políticas e econômicas domésticas.

Como visto, para diferentes amostras de países em desenvolvimento e para diferentes períodos, a privatização figura-se como um componente importante de ajuste estrutural favorável ao crescimento econômico. Todavia, a evidência empírica é também consistente com a noção de que a privatização funciona melhor nos países em desenvolvimento quando é integrada a uma estrutura de desen- 
volvimento mais ampla que agregue outras reformas (SHIN, 1990; RONDINELLI; IACONO, 1996; PARKER; KIRKPATRICK, 2005).

Por outro lado, estudos como os de Cook e Uchida (2003) e Filipovic (2006), também para países em desenvolvimento, encontram uma fraca correlação, algumas vezes negativa, entre processos de privatização e crescimento econômico. Diante de tais resultados, emerge a suspeita de que a privatização, se implementada de forma isolada, não é suficiente para garantir crescimento econômico. Assim, as políticas simuladas neste trabalho conjugam a privatização a outras políticas, a saber, redução na carga tributária e nos níveis de ineficiência do setor público.

Diante de um ambiente no qual as empresas estatais geravam prejuízos ou poucos lucros, na década de 1990 o Brasil adotou um processo de privatização. Pinheiro (1996) destaca os benefícios que esse processo de privatização no Brasil acarretou, como, por exemplo, aumento na eficiência e no nível de produção das empresas e, consequentemente, da lucratividade. Além disso, estimulou um aumento dos investimentos e da propensão a investir. Já Modiano (2000) aponta que não se sabia, ao certo, quais objetivos deveriam ser enfatizados na implementação desse processo, se reduzir a dívida pública, aumentar a competição da economia ou recuperar os investimentos. Com o objetivo inicial de reformar o estado de forma a retirá-lo das atividades produtivas e retorná-lo às suas funções básicas, o processo de privatização, num estágio classificado pelo autor como terceira fase, gerou um ambiente macroeconômico com menos incerteza e mais estabilidade.

Em ambientes de ajuste fiscal, tal como o cenário brasileiro atual sob a vigência da EC 95/2016, muito se questiona os gastos e investimentos nas empresas estatais. Nesse contexto, Pinheiro e Giambiagi (1997) apontam a privatização como uma medida potencial para o ajuste fiscal. Uma vez que o estado brasileiro paga elevados juros e o retorno dos dividendos com a participação acionária das estatais é baixo, concluem que amortizar a dívida pública é a melhor opção para destinação das receitas da privatização. Para Cook e Uchida (2003), altos níveis de dívida pública diminuem o impacto da privatização no crescimento econômico. Países que apresentam esse cenário, na ponderação da decisão de privatização, atribuem maior peso na receita esperada do que nos ganhos de eficiência que por ventura possam ser gerados. Para agregar essa análise, algumas simulações destinam os recursos provenientes da privatização para a amortização da dívida pública.

Considerando os impactos do capital público no crescimento relatados tanto no contexto internacional (ASCHAUER, 1989; BARRO, 1991), quanto no nacional (BEZERRA et al. 2014; GOMES; PEREIRA; BEZERRA, 2019), algumas políticas simuladas neste trabalho destinam os recursos obtidos via privatização para o investimento em infraestrutura pública. Apesar da importância dos investimentos citados, deve-se atentar, no entanto, para Pritchett (2000), que afirma que desconsiderar questões relativas à eficiência do investimento público em países onde o 
governo detém uma fração significativa do investimento ou possui maiores níveis de ineficiência pode gerar problemas de superestimação dos efeitos.

Relativamente a isso, em um trabalho teórico, Agénor (2010) sugere mudanças orçamentárias para aumentos de investimento em infraestrutura e redução de gastos improdutivos. No Brasil, Santana, Cavalcanti e Paes (2012) assinalam que o gasto com a manutenção da administração pública excede o volume conveniente ao equilíbrio das contas públicas e apontam não somente a necessidade de redução desses gastos como, também, que sejam eficientes. Um relatório do Fundo Monetário Internacional (INTERNATIONAL MONETARY FUND, 2015) utilizando o índice de eficiência do investimento público (PIE-X), estimou uma ineficiência média de $40 \%$ nos países pobres, 27\% nos países de renda média e 13\% nos países de maior renda. Assumindo-se que o Brasil possui o nível médio de ineficiência do grupo de países de renda média ao qual pertence, justifica-se a simulação de políticas de redução dos níveis de ineficiência do setor público como complementares às políticas de privatização.

Coelho (2000), ao traçar um possível futuro das privatizações no Brasil, salienta que são necessárias ainda reformas de forma a gerar um sistema de impostos enxuto que permita uma distribuição mais equitativa do ônus fiscal, a partir da produtividade de cada agente. Nesse sentido, Pereira e Ferreira (2018) afirmam que uma condição requerida para potencializar os ganhos de bem-estar de uma política de privatização é que o governo, ao privatizar seu estoque de capital, decida implementar uma política simultânea de redução de impostos.

Ainda, ao analisar o impacto da política de desoneração do imposto sobre o consumo de bens duráveis implementada pelo governo brasileiro com o intuito de estimular a atividade econômica, Costa Júnior, Fantinatti e Teles (2019) apontam que a redução da alíquota do imposto sobre produtos industrializados (IPI) não somente não atingiu o objetivo como também gerou efeito contrário ao gerar contração do produto total. Por fim, sugerem que uma política mais adequada seria uma redução generalizada da alíquota do imposto indireto. No lado da renda, Chieza, Franchescini e Santos (2020) simulam atualizações da tabela de imposto de renda para pessoas físicas, mudando alíquotas, ampliando a arrecadação e, consequentemente, contribuindo para o enfrentamento da crise fiscal. A partir disso, e do fato de que o Brasil possui uma das maiores cargas tributárias dentre os países em desenvolvimento, este trabalho também combina políticas de redução da carga tributária nas simulações de privatizações.

\section{Modelo}

Este trabalho emprega um modelo neoclássico com economia fechada e governo, considerando ineficiência nos gastos e investimentos do setor público. A 
escolha de se trabalhar com uma economia fechada segue uma literatura nacional consolidada, como os trabalhos de Bezerra et al. (2014), Campos e Pereira (2016), Pereira e Ferreira (2018) e Gomes, Pereira e Bezerra (2019). Corroborando isso, Holland (2019), considerando que a abertura comercial da economia brasileira não apresentou mudanças significativas ao longo do tempo, enfatiza que não se espera que tal fator influencie de forma relevante as variáveis macroeconômicas em modelos específicos que analisem a economia brasileira. A economia concebida é composta por uma firma representativa, um agente representativo e o governo.

\subsection{Agente Representativo}

O agente representativo neste modelo, por suposição, vive infinitos períodos. Em cada período $(t)$, divide seu tempo total disponível entre trabalho $\left(\mathrm{H}_{t}\right)$ e lazer $\left(1-\mathrm{H}_{\mathrm{l}}\right.$. Esse agente aufere utilidade por meio do consumo e do lazer. O consumo, nessa modelagem, é dividido entre consumo privado $\left(\mathrm{C} p_{t}\right)$ e de bens públicos $\left(C g_{\mathrm{t}}\right)$. Nesse processo de composição da utilidade, o agente exibe uma taxa de desconto intertemporal $\beta \in(0,1)$, conforme a equação 1 .

$$
U\left(C p_{t}, C g_{t}, H_{t}\right)=\sum_{t=0}^{\infty} \beta^{t}\left(\log \left(C p_{t}+\mu\left(1-\iota_{c}\right) C g_{t}\right)+\psi \log \left(1-H_{t}\right)\right)
$$

Devido à atenção da modelagem na ineficiência do setor público, destaca-se o consumo de bens públicos como base de incidência de ineficiência, representada pelo parâmetro $\iota_{c}$. O parâmetro $\mu$ representa a valoração do consumo de bens e serviços fornecido pelo setor público em relação ao consumo privado. Já o parâmetro $\psi$ representa o peso atribuído ao lazer na composição da utilidade.

$\mathrm{O}$ agente possui, inicialmente e a cada período, um estoque de capital privado $\left(\mathrm{K} p_{\mathrm{t}}\right)$ e títulos acumulados da dívida pública $\left(\mathrm{B}_{\mathrm{t}}\right)$, dos quais aufere as rendas $\left(\mathrm{r} p_{t}\right.$ $\left.\mathrm{K} p_{t}\right)$ e $\left(p_{t} \mathrm{~B}_{t}\right)$, em que $r p_{t}$ e $p_{t}$ representam as respectivas remunerações dos ativos citados. $\mathrm{O}$ agente ainda emprega parte de capital nas empresas estatais, auferindo a renda $\left(\lambda_{t} r e_{t} K e_{t}\right)$, na qual $\lambda_{t} \epsilon(0,1)$ representa a participação no retorno desse capital específico. $\mathrm{O}$ agente aufere renda, ainda, por meio de sua força de trabalho $\left(\mathrm{w}_{\mathrm{t}} \mathrm{H}_{\mathrm{t}}\right)$ e de transferências do governo $(T)$.

Com exceção das transferências governamentais, todas as formas de renda recebidas pelo agente são tributadas pelo governo. Assim, a cada período, a renda disponível ao agente destina-se ao consumo $\left(\mathrm{Cp}_{\mathrm{t}}\right)$, ao investimento $\left(\mathrm{Ip}_{\mathrm{t}}\right)$ - que, por meio da lei de acumulação de capital, disposta na equação 2, gera o estoque de capital que deterá no período seguinte $\left(K p_{t+1}\right)$ - e à aquisição de títulos públicos no período seguinte $\left(B_{t+1}\right)$. As leis de formação dos estoques de capital privado e das empresas estatais estão dispostas nas equações 2 e 3 respectivamente, nas quais os 
parâmetros $\delta$ e $\delta_{e}$ representam as depreciações dos capitais privado e das empresas estatais, respectivamente.

$$
\begin{gathered}
K p_{t+1}=(1-\delta) K p_{t}+I p_{t} \\
K e_{t+1}=\left(1-\delta_{e}\right) K e_{t}+\left(1-\iota_{i}\right) I e_{t}
\end{gathered}
$$

Devido à natureza ineficiente do setor público, juntamente ao fato de o governo investir nas empresas estatais, supõe-se que tais investimentos são passíveis de ineficiência, representada pelo parâmetro $\iota_{i}$. Essa suposição justifica as propostas de privatização das empresas estatais contidas neste trabalho.

Dessa forma, o agente apresenta a restrição orçamentária disposta na equação 4.

$$
\begin{gathered}
\left(1+\tau_{C p, t}\right) C p_{t}+K p_{t+1}+B_{t+1}=\left(1-\tau_{H, t}\right) w_{t} H_{t}+\left(1-\tau_{K e, t}\right) \lambda_{t} r e_{t} K e_{t} \\
+\left((1-\delta)+\left(1-\tau_{K p, t}\right) r p_{t}\right) K p_{t}+\left(1+\left(1-\tau_{B, t}\right) \rho_{t}\right) B_{t}+T_{t}
\end{gathered}
$$

Na equação 4, os parâmetros de tributação $\tau_{\mathrm{H}}, \tau_{\mathrm{B}}, \tau_{K p}$ e $\tau_{K e}$ representam as alíquotas de imposto que incidem sobre as rendas do trabalho, dos títulos da dívida pública, do capital empregado no setor privado e nas estatais. Já $\tau_{c p}$ representa a alíquota sobre o consumo.

Uma vez que o agente representativo dessa economia vive infinitos períodos, deve maximizar utilidade em termos de valor presente. Logo, o problema de otimização do agente é maximizar a função utilidade, da equação 1, sujeita à restrição orçamentária, da equação 4.

\subsection{Firma Representativa}

A economia modelada neste estudo possui um único setor de produção, retratado por uma firma representativa. Para comportar a abordagem acerca da privatização das empresas estatais, assumiu-se que os estoques de capital privado e das estatais são substitutos. Utilizou-se, para tanto, uma função de produção do tipo Cobb-Douglas, especificada na equação 5:

na qual $Y_{t}$ representa o produto agregado da economia; a função de produção utiliza os fatores capital, representado pelo estoque de capital privado $\left(K p_{t}\right)$ e

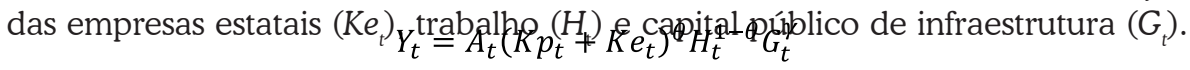


Ressalta-se que este trabalho, por simplicidade, desconsidera a existência de efeitos de congestão na utilização do estoque de infraestrutura.

A função de produção adotada utiliza um parâmetro de tecnologia $\left(A_{t}\right)$, suposto constante. O estoque de capital público $\left(G_{t}\right)$ exibe externalidade, representada pelo parâmetro $\gamma$. Os parâmetros $\theta$ e $(1-\theta)$ representam as elasticidades dos fatores capital e trabalho e exibem retornos constantes de escala. Deve-se lembrar que, nesse caso, o fator capital é considerado uma combinação de capital privado e das estatais. Por formalidade matemática, frisa-se que os parâmetros são não negativos. Nessa modelagem supôs-se que as empresas estatais são portadoras de ineficiência, especificamente no investimento dessas empresas. Tal suposição justifica-se pelo seu vínculo com o setor público, sobretudo nos investimentos.

A utilização de empresas estatais na modelagem de uma firma representativa implica na utilização conjunta de dois diferentes tipos de estoques de capital, privado e das estatais. Assim, a fim de equiparar ambos estoques no processo de otimização, supõe-se que o estoque de capital das empresas estatais responde ao processo de otimização de forma similar ao privado. A ineficiência incide sobre os investimentos das estatais (equação 3). Logo, o estoque de capital pode desempenhar eficiência plena, justificando-se tal suposição.

Com isso, o problema da firma é representado na equação 6:

$$
M A X_{K p, K e, H}\left\{A_{t}\left(K p_{t}+K e_{t}\right)^{\theta} H_{t}^{1-\theta} G_{t}^{\gamma}-r p_{t} K p_{t}-r e_{t} K e_{t}-w_{t} H_{t}\right\}
$$

Uma vez que todos os componentes já foram devidamente apresentados tanto nesta subseção quanto na anterior, dispensam-se novas descrições.

\subsection{Governo}

Na modelagem deste estudo, o governo atua de forma a fornecer bens e serviços públicos $\left(\mathrm{Cg}_{t}\right)$ e transferências de renda $\left(T_{t}\right)$ ao agente representativo. Além disso, realiza investimentos em infraestrutura $\left(J_{t}\right)$ e nas empresas estatais $\left(I e_{t}\right)$.

O financiamento dos gastos citados dá-se por meio de receitas tributárias, de títulos da dívida pública $\left(B_{t}\right)$ e de uma parcela líquida de impostos da remuneração do capital alocado nas estatais $\left(\left(1-\lambda_{t}\right)\left(1-\tau_{K e, t}\right) r e_{t} K e_{t}\right)$.

A receita tributária $\left(R_{t}\right)$ é oriunda do somatório das taxações sobre as fontes de renda do agente, descritas na subseção que trata de sua modelagem e do consumo privado $\left(\tau_{\mathrm{cpt}} \mathrm{Cp}\right)$. A receita tributária encontra-se compilada na equação 7 .

$$
R_{t}=\tau_{C p, t} C p_{t}+\tau_{H, t} w_{t} H_{t}+\tau_{K p, t} r p_{t} K p_{t}+\tau_{K e, t} r e_{t} K e_{t}+\tau_{B, t} \rho_{t} B_{t}
$$


A principal suposição na modelagem do governo é que este mantém o orçamento equilibrado, a cada período. Considera-se, ainda, que neste estudo o governo não se defronta com problema de maximização, como os outros agentes. Assim, pode-se compilar a restrição orçamentária do governo na equação 8:

$$
C g_{t}+J_{t}+I e_{t}+T_{t}+\rho_{t} B_{t}=B_{t+1}-B_{t}+R_{t}+\left(1-\lambda_{t}\right)\left(1-\tau_{K e, t}\right) r e_{t} K e_{t}
$$

Sobre o investimento em infraestrutura $\left(J_{t}\right)$, incide um parâmetro de ineficiência específico representado por $\iota_{j}$. Dessa forma, a dinâmica que rege a lei de formação do estoque de infraestrutura pública é análoga à das empresas estatais. Há, ainda, uma taxa de depreciação específica para esse capital de infraestrutura $\left(\delta_{g}\right)$. A equação 9 descreve essa dinâmica de acumulação.

$$
G_{t+1}=\left(1-\delta_{g}\right) G_{t}+\left(1-\iota_{\jmath}\right) J_{t}
$$

Os parâmetros de política fiscal descritos a seguir representam algumas variáveis consideradas no modelo como proporção do produto: $\alpha_{C g, t}=C g_{t} / Y_{t}$, $\alpha_{I e, t}=I e_{t} / Y_{t} ; \alpha_{J, t}=J_{t} / Y_{t}$, e $\alpha_{B, t}=B_{t} / Y_{t}$. A descrição anterior dessas variáveis dispensa novos comentários.

\subsection{Equilibrio}

Considerando-se o conjunto de parâmetros constantes de ineficiência $\left\{l_{c}, \iota_{j}, \iota_{i}\right\}$ e uma política fiscal tal como $\left\{\tau_{C p, t}, \tau_{H, t}, \tau_{K p, t}, \tau_{K e, t}, \tau_{B, t}, \alpha_{C g, t}, \alpha_{I e, t}, \alpha_{J, t}, \alpha_{B, t}\right\}_{t=0}^{\infty}$, o equilíbrio competitivo é definido como sendo coleções de sequências de decisões individuais do agente representativo da economia modelada, $\left\{C p_{t}, I p_{t}, H_{t}, B_{t+1}\right\}_{t=0}^{\infty}$, de estoques de capital, $\left\{K p_{t}, K e_{t}, G_{t}\right\}_{t=0}^{\infty}$, e das remunerações tanto dos fatores produtivos, $\left\{r p_{t}, r e, w_{t}\right\}_{t=0}^{\infty}$, quanto da dívida pública, $\left\{\rho_{t}\right\}_{t=0}^{\infty}$, tais que satisfazem as seguintes condições:

a) a sequência decisões individuais, $\left\{C p_{t}, I p_{t}, H_{t}, B_{t+1}\right\}_{t=0}^{\infty}$, resolve o problema do agente;

b) a sequência de remunerações dos fatores produtivos, $\left\{r p_{t}, r e_{t}, w_{t}\right\}_{t=0}^{\infty}$ resolve o problema da firma representativa;

c) tanto a restrição orçamentária do governo (equação 8), quanto a restrição de recursos da economia modelada (equação 10) são atendidas:

$$
\begin{aligned}
C p_{t}+I p_{t}+ & \left(1-\iota_{c}\right) C g_{t}+\left(1-\iota_{i}\right) I e_{t}+\left(1-\iota_{j}\right) J_{t}= \\
& =A_{t}\left(K p_{t}+K e_{t}\right)^{\theta} H_{t}^{1-\theta} G_{t}^{\gamma}
\end{aligned}
$$




\section{Calibração}

Para compatibilizar a economia modelada neste trabalho com a realidade a ser analisada, utilizou-se a metodologia de calibração, a qual utiliza dados reais da economia brasileira referentes ao ano de 2014, tal como Gomes, Pereira e Bezerra (2019). Essa escolha, além de conter os dados para todas as variáveis requeridas no processo de calibração, pode representar um cenário aproximado à média dos últimos anos da economia brasileira. Segundo o IBGE (2019), no ano de 2014 a taxa de investimento agregada foi de aproximadamente $20 \%$ e o consumo do governo representou 19,2\% do PIB. Já a média do período 2007-2017 para essas duas variáveis esteve cerca de $19 \%$ e 19,2\%, respectivamente.

Supondo que tal economia esteja em trajetória estacionária no referido ano, obteve-se a solução de estado estacionário do modelo calibrado. Por fins de organização, optou-se pela divisão desta seção em subseções. Além disso, devido às apresentações prévias dos parâmetros na seção que descreve o modelo, e tentando evitar o enfado do leitor, por vezes dispensou-se a repetição de tais descrições.

\subsection{Parâmetros de Preferência e Tecnologia}

Devido à ênfase na abordagem da ineficiência no setor público e a consequente presença de parâmetros de ineficiência na composição de outros parâmetros, optou-se por iniciar a calibração a partir desses parâmetros. Este trabalho assume que o Brasil possui um nível de ineficiência de 27\%. Esse nível representa a média do grupo ao qual pertence segundo a divisão realizada pelo FMI (INTERNATIONAL MONETARY FUND, 2015). Assumiu-se que os parâmetros de ineficiência são iguais em todas as fontes de incidência. Logo, $\mathrm{t}_{\mathrm{c}}=\mathrm{l}_{\mathrm{j}}=\mathrm{l}_{\mathrm{i}}=\mathrm{\iota}=0,27$.

Para a obtenção da valoração do consumo público em relação ao consumo privado $(\mu$ ), seguiu-se Barro (1991) e adotou-se o valor de $\mu=0,5$, caso em que o agente valoriza o consumo público numa intensidade menor do que o consumo privado.

Devido ao fato de existirem diferentes formas de estimar o parâmetro $\gamma$, não existe um consenso na literatura. Aqui, seguiu-se Ferreira (1993) e adotou-se o valor de 0,09. Embora tal parâmetro tenha sido estimado para a economia americana e haja diferenças entre tal economia e a brasileira, além de uma defasagem temporal, optou-se por tal uso primeiramente por conveniência e, depois, sob o argumento de ser adotado na literatura nacional em estudos com diferentes abordagens. ${ }^{1}$ Assim, $\gamma=0,09$.

$1 \quad$ Ver Campos e Pereira (2016) e Gomes, Pereira e Bezerra (2019). 
Da forma funcional da função de produção onde se constata que o capital das empresas estatais é substituto do capital privado e da suposição de ineficiência dos investimentos públicos nas empresas estatais, para evitar migração de capital o modelo deve considerar os retornos dos capitais privado e das estatais iguais. Logo, $r=r g$.

Em relação às horas trabalhadas $(H)$, seguindo Cooley e Prescott (1995), assumiu-se que o agente representativo dedica um terço do tempo disponível ao trabalho, uma espécie de jornada média de trabalho. O parâmetro tecnológico (A) é calibrado como forma de normalizar o produto de estado estacionário. Logo, calibrou-se $A=15,1418$. Já o peso do lazer na utilidade $(\psi)$ ajusta-se na intenção de compatibilizar as horas trabalhadas em um terço. Tem-se, então, $\psi=1,2333$.

Para as depreciações referentes ao estoque de capital privado $(\delta)$, das estatais $\left(\delta_{e}\right)$ e de infraestrutura pública $\left(\delta_{g}\right)$ utilizaram-se dados referentes à média ${ }^{2}$ dos anos de 2003 a 2008. A calibração do $\delta$ é realizada por meio da lei de formação do estoque de capital privado no estado estacionário. Por questões de conveniência e compatibilização dos dados, utilizam-se as variáveis como proporção do produto. Assim, pode-se denotar $\delta=(\mathrm{Ip} / \mathrm{Y}) /(\mathrm{Kp} / \mathrm{Y})$. A inexistência de dados desagregados referentes ao estoque de capital das estatais implica diretamente uma agregação nos dados das empresas privadas e estatais. A partir de dados do Ipeadata (2019) e IBGE (2019), devidamente deflacionados, extraíram-se as relações médias para o período adotado, $\mathrm{Ip} / \mathrm{Y}=0,1738 \mathrm{e} \mathrm{Kp} / \mathrm{Y}=1,9622$. A simplificação adotada implica a igualdade seguinte, $\delta=\delta_{e}=0,0886$. Tal resultado reflete a suposição de que as estatais atuam de forma a maximizar o lucro.

Analogamente, calibra-se $\delta_{g}$. Assim, a partir de dados da Secretaria do Tesouro Nacional (STN, 2014), da Controladoria Geral da União (CGU) (2010, 2011 , 2012, 2013, 2014), do Ipeadata (2019) e IBGE (2019), tem-se as proporções J/ $\mathrm{Y}=0,0168$ e $\mathrm{G} / \mathrm{Y}=0,3577$, das quais se obtém $\delta_{g}=0,0494$.

Para calibrar o parâmetro utilizam-se as condições de primeira ordem da firma, $\operatorname{como} \theta=(\mathrm{Kp}+\mathrm{Ke}) \mathrm{r} / \mathrm{Y}$. A remuneração do capital como proporção do produto a custo de fatores é contabilizada por meio da soma do excedente operacional bruto com uma parcela equivalente a um terço do rendimento misto bruto, referente aos autônomos. Dessa forma, tem-se calibrado $\theta=0,4221$. E, de forma trivial, tem-se $(1-\theta)=0,5779$.

2 Na ausência de um dado mais recente, o objetivo do uso da média é evitar pontos específicos de possíveis ciclos, evitando-se, assim, a superestimação ou subestimação desse parâmetro. O último ano utilizado, 2008, reflete o término da série de estoque de capital disponível pelo Ipeadata, calculados por Morandi e Reis (2004). 
Tabela 1 - Síntese da calibração dos parâmetros de tecnologia e preferência

\begin{tabular}{ccccccccccc}
\hline$\beta$ & $\delta$ & $\delta_{e}$ & $\delta_{g}$ & $\gamma$ & $\mu$ & $\theta$ & $(1-\theta)$ & $\iota$ & $A$ & $\psi$ \\
\hline 0,9267 & 0,0886 & 0,0886 & 0,0494 & 0,09 & 0,5 & 0,4221 & 0,5779 & 0,27 & 15,1418 & 1,2333 \\
\hline
\end{tabular}

Fonte: Elaboração própria.

\subsection{Parâmetros Fiscais}

A partir do Boletim do Banco Central do Brasil (BRASIL, 2014) foram extraídas as informações referentes à dívida pública (B). Em 2014, a dívida pública líqui$\mathrm{da}^{3}$ foi equivalente a $32,58 \%$ do PIB. Já o pagamento de juros da dívida pública como proporção do produto $(\rho \mathrm{B} / \mathrm{Y})$, no mesmo ano, foi de 5,38\%. Dessa relação obtém-se o pagamento da dívida em termos nominais, $\rho$ nominal $=0,1653$. O pagamento em termos reais pode ser obtido da seguinte forma: $\rho=\left(\rho_{\text {nominal }}-\mathrm{IPCA}_{2014}\right) /$ $\left(1+\mathrm{IPCA}_{2014}\right)$. Assim, tem-se calibrado $\rho=0,0951$.

Para a obtenção da alíquota da dívida $(\tau B)$, utilizou-se a legislação vigente acerca dos impostos retidos na fonte com base de incidência sobre as aplicações financeiras (Lei $\left.n^{\circ} 11.033 / 2004\right)$. Considerando-se as faixas de renda e suas respectivas alíquotas, calculou-se uma alíquota média que, nesse caso, representa o parâmetro de interesse. Logo, $\tau_{\mathrm{B}}=0,1679$.

De posse da variável $\rho$ e do parâmetro $\tau_{\mathrm{B}}$, pode-se calibrar o fator de desconto intertemporal $\beta$ e os parâmetros de política fiscal referentes à tributação do capital $\left(\tau_{K p}, \tau_{K e}\right)^{4}$. Obtém-se $\beta$ por meio das condições de primeira ordem do consumidor. Tem-se, então, $\beta=1 /\left(1+\rho-\rho \tau_{\mathrm{B}}\right)=0,9267$.

Considerando-se a incidência conjunta da carga tributária sobre os rendimentos do capital e dos títulos públicos como fração do produto $\left(\tau_{c, d p}\right)$ tem-se que, no ano de 2014, a soma da arrecadação dos rendimentos do capital público e das estatais, bem como da dívida pública gera $\tau_{\mathrm{c}, \mathrm{dp}}=0,0760$. A ausência de dados desagregados para os capitais privado e das estatais implica na necessidade da suposição de igualdade entre as alíquotas tributárias de tais variáveis. Logo $\tau_{\mathrm{Kp}}=\tau_{\mathrm{Ke}}$, doravante $\tau_{\mathrm{K}}$.

3 Utilizou-se o saldo líquido da dívida pelo fato de ser um indicador relevante para a capacidade de solvência fiscal do país. Tal escolha é amplamente adotada na literatura, por exemplo, nos estudos de Bezerra et al. (2014), Campos e Pereira (2016) e Gomes, Pereira e Bezerra (2019). Para outras sugestões, ver Athayde e Vianna (2015).

4 Para o cálculo das alíquotas são utilizados dados do relatório Carga tributária no Brasil 2015: análise por tributo e base de incidência (BRASIL, 2016). Tributação sobre o retorno do capital e títulos: impostos de renda retidos na fonte + IR de pessoa física + IR de pessoa jurídica do lucro real + CSLL do lucro real + Imposto Territorial Rural (ITR) + IPVA + ITCD + IPTU + ITBI + tributos sobre transações financeiras + outros tributos. 
Tal suposição aplicada em $\tau_{\mathrm{c}, \mathrm{dp}}{ }^{5}$ gera o valor da alíquota tributária incidente sobre o capital. Assim, $\tau_{\mathrm{K}}=0,1586$.

De acordo com o relatório anual Carga Tributária no Brasil 2015 (BRASIL, 2016), ${ }^{6}$ em 2014 a arrecadação de impostos sobre o consumo como proporção do produto foi de $16 \%$. Já o consumo como proporção do PIB foi de $62,9 \%$. Tem-se, assim, . Por outro lado, a arrecadação sobre os rendimentos do trabalho em proporção do produto foi de $8,28 \%$. Utilizando-se o valor já calibrado $(1-\theta)=0,5779$, tem-se $\tau_{\mathrm{H}}=0,1433$.

No ano de 2014, as proporções do produto referentes aos investimentos privado, em infraestrutura pública e nas estatais foram de $13,51 \%$, $2,96 \%$ e $1,40 \%$, respectivamente. Já o consumo do governo e a dívida pública foram de $19,15 \%$ e $32,58 \%$, respectivamente. Assim, calibrou-se $\alpha_{C g}=0,1915, \alpha_{I e}=0,0140, \alpha_{J}=0,0296$ e $\alpha_{B}=0,3258$.

Tal como realizado por Bezerra et al. (2014), a participação do setor público no excedente operacional bruto das empresas estatais foi obtida por uma média da participação acionária da União ponderada pelo total do investimento em cada respectiva empresa estatal. Para tanto, consideraram-se 23 empresas públicas e 16 sociedades de economia mista nas quais a União possui participação acionária majoritária, resultando em $63,26 \%$. Isso implica, por complementaridade, que a participação privada nas empresas estatais é de 36,74\%. Logo, $\lambda=0,3674$.

Tabela 2 - Síntese da calibração dos parâmetros fiscais

\begin{tabular}{ccccccccc}
\hline$\tau_{\text {Cp }}$ & $\tau_{\mathrm{K}}$ & $\tau_{\mathrm{B}}$ & $\tau_{\mathrm{H}}$ & $\alpha_{\mathrm{Cg}}$ & $\alpha_{\mathrm{le}}$ & $\alpha_{\mathrm{J}}$ & $\alpha_{\mathrm{B}}$ & $\lambda$ \\
\hline 0,2544 & 0,1586 & 0,1679 & 0,1433 & 0,1915 & 0,0140 & 0,0296 & 0,3258 & 0,3674 \\
\hline
\end{tabular}

Fonte: Elaboração própria.

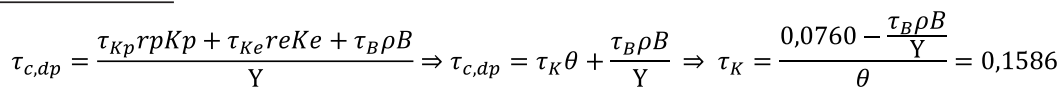

Os tributos sobre o consumo utilizados foram: Imposto sobre Circulação de Mercadorias e Serviços (ICMS) + Imposto sobre Produtos Industrializados (IPI) + Cofins + Imposto sobre Serviços (ISS) + Cide - combustível + PIS (cumulativo e não cumulativo) + Simples Nacional + contribuição social sobre o lucro líquido do lucro presumido + imposto de renda de pessoa jurídica do lucro presumido + Cide - remessas + taxas sobre o comércio exterior + taxas de prestação de serviço e poder de polícia + outras contribuições sociais e econômicas. Já em relação à tributação sobre o trabalho utilizou-se: + contribuição para o INSS + CPSS + previdência dos estados e municípios + Fundo de Saúde Militar (beneficiário) + contribuição para o FGTS + salário educação + contribuição para o sistema S + PIS + Pasep + outros. 


\section{Simulações e Resultados}

As políticas de privatização são simuladas tanto de forma isolada quanto compostas por políticas de redução de ineficiência do setor público e de alíquotas tributárias. Além disso, visando obter resultados diferentes, há diferenciação na destinação das receitas oriundas da privatização, a lembrar, para infraestrutura pública e para reduzir a dívida pública.

Supõe-se que a implementação das políticas não onera o estado. Tal suposição fundamenta-se no argumento de que a implementação depende, em grande medida, de esforços políticos. A elaboração e implementação sem custos adicionais são factíveis via mudanças na legislação referente à privatização e à tributação e, no caso específico da redução de ineficiência, de um mecanismo de metas no provimento de serviços públicos, por exemplo.

\subsection{Medida de Bem-Estar}

Cooley e Hansen (1992) propõem uma forma de aferir bem-estar avaliando-se em termos de um componente da função de produção antes da intervenção analisada, o consumo privado, suficiente para compensar as variações de todas as variáveis e, consequentemente, da utilidade, após a implementação da política.

Interpreta-se tal metodologia como sendo uma equivalência entre o aumento percentual no consumo privado $(C p)$ de estado estacionário inicial, mantendo-se constantes consumo público $(\mathrm{Cg})$ e horas trabalhadas $(\mathrm{H})$ suficientemente para gerar o mesmo nível de utilidade após a implementação da proposta, de forma que a igualdade da equação seja satisfeita.

$$
\begin{gathered}
\sum_{t=1}^{\infty} \beta^{t}\left(\log \left(C p_{t}^{A P}(1+x)+\mu\left(1-\iota_{c}\right) C g_{t}^{A P}\right)+\psi \log \left(1-H_{t}^{A P}\right)\right)= \\
=\sum_{t=1}^{\infty} \beta^{t}\left(\log \left(C p_{t}^{D P}+\mu\left(1-\iota_{c}\right) C g_{t}^{D P}\right)+\psi \log \left(1-H_{t}^{D P}\right)\right)
\end{gathered}
$$

Na equação 11 , o sobrescrito $(A P)$ refere-se às variáveis antes da implementação da política, isto é, no estado estacionário calibrado, e o sobrescrito (DP) refere-se às variáveis após a política entrar em vigor. 


\subsection{Simulações de Políticas}

As políticas realizadas neste artigo foram:

a) política de privatização 1 : privatização completa do estoque de capital público das empresas estatais $(\mathrm{Ke})$, mantendo-se constantes os níveis de ineficiência de $27 \%$ do setor público e a carga tributária vigente e destinando-se o bônus (os recursos auferidos com a privatização) para o investimento em infraestrutura pública;

b) política de privatização 2: privatização similar à política 1, com redução dos níveis de ineficiência de $27 \%$ para $13 \%$;

c) política de privatização 3: privatização similar à política 1, com redução na carga tributária brasileira em $10 \%$, ou seja, igualmente em todas as alíquotas;

d) política de privatização 4: combinação das políticas 1, 2 e 3;

e) todas as políticas são realizadas em dois cenários diferentes, considerando-se o direcionamento das receitas de privatização aos investimentos em infraestrutura e ao abatimento da dívida pública, totalizando oito simulações de políticas de privatização. Uma prévia dos resultados, no que diz respeito ao bem-estar, encontra-se na Tabela 3.

Tabela 3 - Síntese dos ganhos de bem-estar gerados pelas simulações das políticas de privatização

\begin{tabular}{ccc}
\hline Políticas & Bônus para infraestrutura & Bônus para dívida pública \\
\hline Privatização 1 & 0,5313 & 0,5313 \\
Privatização 2 & 3,4057 & 3,4057 \\
Privatização 3 & 1,4975 & 1,4975 \\
Privatização 4 & 4,4470 & 4,4470 \\
\hline
\end{tabular}

Fonte: Elaboração própria.

A Tabela 4 apresenta os resultados da política de privatização 1. Essa política consiste na privatização total das empresas estatais, mantendo-se constante os níveis de ineficiência de $27 \%$ do setor público e a carga tributária brasileira. Além disso, o ambiente simulado considera a vigência da EC 95/2016 por 10 anos no que diz respeito aos gastos públicos. Há, no entanto, a especificidade de que nessa política a receita gerada pela privatização é destinada ao investimento em infraestrutura pública. 
Tabela 4 - Efeitos de crescimento e bem-estar da política de privatização $1^{*}$

\begin{tabular}{lcccccccc}
\hline Anos após & $\mathbf{1}$ & $\mathbf{4}$ & $\mathbf{8}$ & $\mathbf{1 2}$ & $\mathbf{2 0}$ & $\mathbf{5 0}$ & $\mathbf{1 0 0}$ & $\mathbf{2 0 0}$ \\
\hline Variáveis & \multicolumn{1}{c}{} & & & & & & \\
\hline Consumo privado & 1,0043 & 1,0034 & 1,0027 & 1,0027 & 1,0024 & 1,0020 & 1,0019 & 1,0019 \\
Consumo bens públicos & 1,0000 & 1,0000 & 1,0000 & 0,9961 & 0,9959 & 0,9956 & 0,9955 & 0,9955 \\
Investimento privado & 1,0517 & 1,0523 & 1,0520 & 1,0532 & 1,0533 & 1,0531 & 1,0530 & 1,0530 \\
Salários & 1,0018 & 1,0011 & 1,0005 & 1,0001 & 0,9998 & 0,9994 & 0,9993 & 0,9993 \\
Investimento público & 0,2876 & 0,2875 & 0,2874 & 0,2872 & 0,2872 & 0,2871 & 0,2870 & 0,2870 \\
Produto & 0,9976 & 0,9971 & 0,9966 & 0,9961 & 0,9959 & 0,9956 & 0,9955 & 0,9955 \\
Capital privado & 0,9995 & 0,9983 & 0,9972 & 0,9965 & 0,9961 & 0,9956 & 0,9955 & 0,9955 \\
Dívida pública & 0,9974 & 0,9970 & 0,9965 & 0,9961 & 0,9959 & 0,9956 & 0,9955 & 0,9955 \\
Gastos governo & 0,9999 & 0,9995 & 0,9990 & 0,9985 & 0,9977 & 0,9961 & 0,9955 & 0,9955 \\
Horas trabalho & 0,9958 & 0,9961 & 0,9962 & 0,9961 & 0,9961 & 0,9962 & 0,9962 & 0,9962 \\
Receita tributária & 1,0009 & 1,0001 & 0,9996 & 0,9994 & 0,9991 & 0,9987 & 0,9986 & 0,9986 \\
\hline
\end{tabular}

Fonte: Elaboração própria.

Nota: Efeito de bem-estar: $x=0,5313$; *destina as receitas obtidas com a privatização para o investimento em infraestrutura pública.

Com a implementação da política 1, o investimento privado apresentaria uma variação positiva, superior a $5 \%$. Uma vez que tal variação permanece até o longo prazo, pode-se dizer que o choque gerado pela privatização causa essa variação de forma sustentada.

A variação positiva no desempenho do consumo privado $(0,5 \%)$ juntamente com a redução, ainda que diminuta, das horas trabalhadas seriam suficientes para compensar a queda no consumo de bens públicos após o período de vigência da EC 95/2016, de forma a gerar um ganho de bem-estar de 0,53\%. Atenta-se à sutileza da interpretação da queda brusca do investimento em infraestrutura pública, pois, uma vez que a destinação do bônus da privatização para essa rubrica ocorre de uma única vez, no segundo período os investimentos retornam ao patamar inicial (proporção do produto), gerando a redução observada.

Caso as receitas oriundas da privatização fossem destinadas ao abatimento da dívida pública, a dívida líquida passaria do percentual calibrado de $32 \%$ do produto para $25 \%$ do produto. O ganho de bem-estar é similar ao obtido no caso das destinações à infraestrutura. Os resultados completos estão dispostos na Tabela 8, no Apêndice A.

Vê-se que os ganhos gerados por políticas puras de privatização (política 1 em ambas configurações de destinação do bônus da privatização) geram resultados módicos. Dada a modelagem considerada neste estudo na qual o governo possui ineficiência em seus gastos e investimentos, considera-se Lucio (2017) ao gerar ganhos de bem-estar por meio de políticas de redução dos níveis de ineficiência do setor público. Assim, espera-se que reduzindo-se o nível de ineficiência calibrado (27\%), combinado com a política de privatização simulada, os resultados, em termos de ganhos de bem-estar e/ou macroeconômicos, sejam potencializados. 
Dado o exposto, considera-se agora a política de privatização 2. Essa política combina a política 1 com uma redução dos níveis de ineficiência para 13\%. Pode-se reduzir ineficiência por meio de mecanismos de gestão do setor público, como cobrança de resultados e metas de servidores, melhoria nos processos institucionais, criação e aprimoramento de mecanismos efetivos de fiscalização e transparência e/ou de um sistema efetivo de avaliação de políticas públicas visando evitar misallocation, dentre outras formas. Tal redução simula uma situação na qual o Brasil fosse tão eficiente quanto a média de países desenvolvidos, tal como dividido pelo Fundo Monetário Internacional (INTERNATIONAL MONETARY FUND, 2015). Salvo essa especificidade, a política 2 carrega as demais características da política 1 (cenário de vigência da EC 95/2016 e destinação das receitas da privatização para infraestrutura). A Tabela 5 apresenta os resultados macroeconômicos obtidos via simulação de implementação dessa política conjunta.

Tabela 5 - Efeitos de crescimento e bem-estar da política de privatização 2*

\begin{tabular}{lcccccccc}
\hline Anos após & $\mathbf{1}$ & $\mathbf{4}$ & $\mathbf{8}$ & $\mathbf{1 2}$ & $\mathbf{2 0}$ & $\mathbf{5 0}$ & $\mathbf{1 0 0}$ & $\mathbf{2 0 0}$ \\
\hline Variáveis & & & & & & & & \\
\hline Consumo privado & 0,9984 & 0,9950 & 0,9948 & 0,9979 & 1,0026 & 1,0138 & 1,0179 & 1,0185 \\
Consumo bens públicos & 1,0000 & 1,0000 & 1,0000 & 0,9921 & 0,9973 & 1,0077 & 1,0114 & 1,0119 \\
Investimento privado & 1,0202 & 1,0330 & 1,0424 & 1,0516 & 1,0586 & 1,0673 & 1,0700 & 1,0704 \\
Salários & 1,0087 & 1,0068 & 1,0072 & 1,0090 & 1,0140 & 1,0250 & 1,0290 & 1,0296 \\
Investimento público & 0,2849 & 0,2850 & 0,2855 & 0,2861 & 0,2876 & 0,2906 & 0,2916 & 0,2918 \\
Produto & 0,9882 & 0,9885 & 0,9901 & 0,9921 & 0,9973 & 1,0077 & 1,0114 & 1,0119 \\
Capital privado & 0,9969 & 0,9911 & 0,9885 & 0,9892 & 0,9941 & 1,0066 & 1,0113 & 1,0119 \\
Dívida pública & 0,9882 & 0,9888 & 0,9906 & 0,9928 & 0,9978 & 1,0078 & 1,0114 & 1,0119 \\
Gastos governo & 1,0088 & 1,0326 & 1,0595 & 1,0819 & 1,1166 & 1,1798 & 1,2027 & 1,2060 \\
Horas trabalho & 0,9797 & 0,9818 & 0,9830 & 0,9832 & 0,9835 & 0,9831 & 0,9829 & 0,9828 \\
Receita tributária & 0,9934 & 0,9916 & 0,9924 & 0,9951 & 1,0000 & 1,0107 & 1,0146 & 1,0151 \\
\hline
\end{tabular}

Fonte: Elaboração própria.

Notas: Efeito de bem-estar: $x=3,4057 ;^{*}$ combinação da política 1 com redução do nível de ineficiência para $13 \%$. Ou seja, $\mathrm{t}=0,13$.

Muito embora o consumo privado apresente uma redução nos primeiros períodos e esboce variações positivas somente no médio prazo (20 anos) e, passada a vigência da EC 95/2016, o consumo de bens públicos apresente leve redução e recupere-se somente por volta do $50^{\circ}$ período, essa política geraria um ganho de bem-estar de 3,4\%.

A partir das variações dos consumos e do ganho de bem-estar citado, e da forma funcional da função utilidade, tem-se que a maior parte desse bem-estar advém do aumento do lazer do agente. Pela redução nas horas trabalhadas, tem-se um fator explicativo para a queda no produto. No entanto, nesse caso, tem-se uma sinalização de ganhos de produtividade elucidados tanto pelo teor da política 
quanto pelo crescimento do produto, quando da permanência das horas trabalhadas abaixo do estado estacionário inicial. Analogamente ao caso anterior, simulou-se um cenário alternativo no qual o bônus da privatização fosse utilizado para abater da dívida pública. Não se observou diferença nos ganhos de bem-estar. Os resultados estão dispostos na Tabela 9, no Apêndice A.

Uma vez constatado tanto o aumento no produto quanto os ganhos de bem-estar pela combinação da política de privatização com a política de redução de ineficiência, considera-se uma outra forma de combinação possível, a política de privatização 3. Esta, assim como a política 2, carrega os aspectos da política 1 . A combinação, nesse caso, dá-se por meio de uma redução na carga tributária brasileira e tem seus resultados dispostos na Tabela 6. Adotou-se uma redução arbitrária de $10 \%$ em todas as alíquotas.

Tabela 6 - Efeitos de crescimento e bem-estar da política de privatização 3*

\begin{tabular}{lcccccccc}
\hline Anos após & $\mathbf{1}$ & $\mathbf{4}$ & $\mathbf{8}$ & $\mathbf{1 2}$ & $\mathbf{2 0}$ & $\mathbf{5 0}$ & $\mathbf{1 0 0}$ & $\mathbf{2 0 0}$ \\
\hline Variáveis & & & & & & & & \\
\hline Consumo privado & 1,0082 & 1,0228 & 1,0341 & 1,0354 & 1,0403 & 1,0450 & 1,0462 & 1,0464 \\
Consumo bens públicos & 1,0000 & 1,0000 & 1,0000 & 1,0377 & 1,0409 & 1,0446 & 1,0458 & 1,0460 \\
Investimento privado & 1,1534 & 1,1426 & 1,1413 & 1,1275 & 1,1251 & 1,1263 & 1,1272 & 1,1273 \\
Salários & 0,9867 & 0,9973 & 1,0060 & 1,0112 & 1,0153 & 1,0195 & 1,0207 & 1,0208 \\
Investimento público & 0,2937 & 0,2957 & 0,2976 & 0,2992 & 0,3001 & 0,3012 & 0,3016 & 0,3016 \\
Produto & 1,0186 & 1,0254 & 1,0320 & 1,0377 & 1,0409 & 1,0446 & 1,0458 & 1,0460 \\
Capital privado & 1,0080 & 1,0262 & 1,0423 & 1,0521 & 1,0584 & 1,0640 & 1,0655 & 1,0657 \\
Dívida pública & 1,0211 & 1,0272 & 1,0336 & 1,0382 & 1,0411 & 1,0447 & 1,0458 & 1,0460 \\
Gastos governo & 1,0009 & 1,0041 & 1,0088 & 1,0138 & 1,0224 & 1,0390 & 1,0451 & 1,0460 \\
Horas trabalho & 1,0323 & 1,0282 & 1,0259 & 1,0262 & 1,0252 & 1,0247 & 1,0246 & 1,0246 \\
Receita tributária & 0,9119 & 0,9222 & 0,9298 & 0,9328 & 0,9363 & 0,9400 & 0,9411 & 0,9412 \\
\hline
\end{tabular}

Fonte: Elaboração própria.

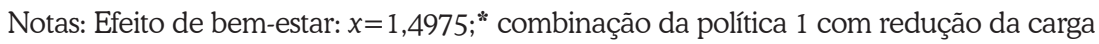
tributária em $10 \%$.

Essa política tem uma característica de incentivar os investimentos privados. Constatou-se, portanto, um aumento de $15 \%$ nos investimentos logo no primeiro período e, depois de certa redução ao longo do tempo, estabilizou-se no longo prazo $12 \%$ superior ao estado estacionário inicial. Tais valores são considerados bastante significativos.

O investimento privado proporciona o crescimento do produto de forma que no primeiro período já se observa um crescimento de quase $2 \%$. No longo prazo, o produto seria 4,6\% maior em relação a um cenário sem a implementação da política. O aumento do produto, por sua vez, fomenta o aumento dos consumos, mas, por outro lado, requer um aumento das horas trabalhadas. Destaca-se que as va- 
riações positivas dos consumos são suficientes para compensar a redução do lazer do indivíduo de forma a gerar um ganho de bem-estar de aproximadamente 1,5\%.

Uma vez destacados os resultados positivos da implementação dessa política conjunta, deve-se atentar aos custos envolvidos e facilmente perceptíveis em termos das finanças públicas, dado que se observa uma redução nas receitas tributárias. Todavia, frisa-se que os efeitos de crescimento geram aumentos sinérgicos nas bases de incidência de tributação, consumo, trabalho e capital, de forma que a receita tributária é reduzida em menor proporção de que a carga tributária. Novamente, simulou-se o cenário de destinação das receitas auferidas no processo de privatização para abater a dívida pública. Constatou-se um ganho de bem-estar muito aproximado, no caso do abatimento da dívida pública (1,49\%). Os resultados completos estão dispostos na Tabela 10, no Apêndice A.

Observou-se que as políticas de privatização, quando adotadas de maneira simultânea às outras políticas, potencializam os ganhos de bem-estar. Isso posto, espera-se que a simultaneidade das três políticas anteriores potencialize ainda mais esses ganhos e/ou implique em maior estabilidade as outras variáveis macroeconômicas.

Supondo-se agora que, além de o ambiente político permitir a adoção conjunta de uma política de privatização com redução dos níveis de ineficiência do setor público e de redução da carga tributária, o governo esteja disposto a adotar tal política. A suposição da disposição do governo em implementar essa política carrega consigo uma outra suposição, a saber, a de que o governo pode não atuar em prol do bem comum, pois alguns resultados afetariam negativamente a atividade do governo via redução das receitas tributárias.

Assim, apesar de ser uma suposição deveras otimista, a Tabela 7 apresenta os resultados gerados pela política de privatização 4 .

Tabela 7 - Efeitos de crescimento e bem-estar da política de privatização 4 *

\begin{tabular}{lllllllll}
\hline Anos após & $\mathbf{1}$ & $\mathbf{4}$ & $\mathbf{8}$ & $\mathbf{1 2}$ & $\mathbf{2 0}$ & $\mathbf{5 0}$ & $\mathbf{1 0 0}$ & $\mathbf{2 0 0}$ \\
\hline Variáveis & & & & & & & & \\
\hline Consumo privado & 1,0023 & 1,0147 & 1,0268 & 1,0305 & 1,0408 & 1,0575 & 1,0631 & 1,0639 \\
Consumo bens públicos & 1,0000 & 1,0000 & 1,0000 & 1,0337 & 1,0426 & 1,0576 & 1,0627 & 1,0634 \\
Investimento privado & 1,1224 & 1,1230 & 1,1307 & 1,1264 & 1,1313 & 1,1417 & 1,1456 & 1,1461 \\
Salários & 0,9933 & 1,0029 & 1,0128 & 1,0203 & 1,0300 & 1,0457 & 1,0511 & 1,0518 \\
Investimento público & 0,2910 & 0,2932 & 0,2957 & 0,2981 & 0,3006 & 0,3050 & 0,3064 & 0,3066 \\
Produto & 1,0093 & 1,0169 & 1,0256 & 1,0337 & 1,0426 & 1,0576 & 1,0627 & 1,0634 \\
Capital privado & 1,0054 & 1,0190 & 1,0335 & 1,0445 & 1,0567 & 1,0761 & 1,0825 & 1,0835 \\
Dívida pública & 1,0120 & 1,0192 & 1,0278 & 1,0351 & 1,0435 & 1,0578 & 1,0627 & 1,0634 \\
Gastos governo & 1,0100 & 1,0381 & 1,0712 & 1,1002 & 1,1463 & 1,2318 & 1,2628 & 1,2673 \\
Horas trabalho & 1,0161 & 1,0140 & 1,0127 & 1,0131 & 1,0123 & 1,0113 & 1,0111 & 1,0110 \\
Receita tributária & 0,9051 & 0,9146 & 0,9237 & 0,9289 & 0,9375 & 0,9515 & 0,9563 & 0,9570 \\
\hline
\end{tabular}

Fonte: Elaboração própria.

Notas: Efeito de bem-estar: $\mathrm{x}=4,4470^{*}$ políticas 1, 2 e 3 implementadas de forma simultânea. 
Primeiramente, nota-se que o efeito dessa política sobre o bem-estar seria, como pretendido, potencializado. Nesse caso, o resultado seria aproximadamente um aumento equivalente a 4,45\% no consumo privado de estado estacionário, tal como dispõe a medida proposta neste trabalho. Tal resultado é fruto da variação positiva de ambos os consumos e da variação do lazer do indivíduo, em menor magnitude vis-à-vis a política 3.

Além dos ganhos de produtividade na economia gerados pela política de redução de ineficiência, tem-se que parte significativa desse crescimento econômico é garantido pelo investimento privado que apresenta crescimento sustentado ao longo do tempo. A capacidade de recuperação da economia frente a essa política conjunta pode ser visualizada por meio dos resultados da receita tributária, pois esta começa a se recuperar da redução de 10\% na carga tributária logo no primeiro período e, muito embora não retorne ao patamar inicial, apresenta um aumento superior a cinco pontos percentuais, superando $95 \%$ da receita inicial no médio e longo prazos.

A parte da política que representa a implementação da redução dos níveis de ineficiência atuam, de certa forma, a compensar as perdas de receita tributária por ser, por definição, um mecanismo que aumenta o volume de recursos de fato empregados no fornecimento de bens e serviços públicos. Como padrão das análises deste trabalho, simulou-se a dívida sendo reduzida pela receita oriunda das privatizações. Os resultados completos encontram-se na Tabela 11, disposta no Apêndice A.

Se implementadas, as políticas de privatização aqui propostas gerariam resultados positivos para o indivíduo. As políticas conjuntas repercutiriam positivamente tanto para o agente quanto para os principais agregados macroeconômicos. Uma vez que as relações, e talvez as direções de resposta, das variáveis foram definidas por cada política específica e que os níveis de reduções tanto de ineficiência quanto de carga tributária foram arbitrários, as análises podem ser extrapoladas de forma a atribuir novos valores, pois devem existir outras combinações possíveis dos valores desses parâmetros capazes de se obter resultados positivos similares aos observados nesta seção.

A escolha das variáveis descritas com maior atenção reflete o foco do trabalho. Contudo, análises pormenorizadas de qualquer variável ficam a cargo do leitor a partir das tabelas, inclusive as dispostas no Apêndice A, com auxílio das equações do modelo. 


\section{Considerações Finais}

Este trabalho analisou os efeitos de políticas de privatização das empresas estatais nos agregados macroeconômicos e no nível de bem-estar. Tais políticas foram compostas, além da privatização em si, por políticas de redução de ineficiência do setor público e de alíquotas tributárias. Além disso, simularam-se cenários com diferentes destinações das receitas geradas pela privatização, a lembrar, para financiar infraestrutura pública e para reduzir a dívida pública. Todas as políticas consideram um cenário fiscal no qual vigora a EC 95/2016.

Observou-se que as políticas de privatização implementadas de maneira isolada, ainda que apresentem resultados pouco expressivos, como, por exemplo, ganhos de bem-estar de aproximadamente $0,5 \%$, causariam uma espécie de sinergia no setor privado de forma a aumentar o investimento em $5 \%$. Os resultados positivos justificam um possível esforço de implementação.

Considerando-se a composição da política de privatização com apenas uma das duas utilizadas, as simulações de políticas que envolvem redução da carga tributária apresentam melhores resultados nos agregados macroeconômicos, em especial, em relação ao investimento e ao crescimento do produto. Essa combinação apresenta potencial para alcançar até $15 \%$ de crescimento de curto prazo no investimento e 4,5\% de crescimento do produto de longo prazo. Por outro lado, as políticas simuladas de privatização combinadas com redução de ineficiência alcançam melhores resultados em termos de ganhos de bem-estar.

Se, por um lado, os resultados em relação ao crescimento do produto representam o principal resultado macroeconômico, por outro lado o bem-estar figura-se como o principal objetivo do indivíduo. Nesse caso, ainda que a modelagem do governo neste trabalho não contemple um problema de maximização de bem-estar social, destaca-se que deve implementar políticas baseando-se nesse mote. Nesse sentido, no que diz respeito às variações das políticas via diferenciação da destinação das receitas oriundas da privatização, observou-se um ganho de bem-estar semelhante independentemente dessa destinação.

Mostrou-se, portanto, os benefícios potenciais de políticas de privatização das empresas estatais, sobretudo quando combinadas com outras políticas. Tentou-se abordar uma variedade de combinações de políticas, respeitando-se a factibilidade das propostas na tentativa de munir os policymakers com estimativas de resultados de opções variadas para orientação nas tomadas de decisão, pois, caso alguma política apresente em determinado momento viabilidade questionável, seja por requerer maior manobra política, seja por qualquer outra razão, possa ser desconsiderada ou implementada parcialmente. 


\section{Referências}

AGÉNOR, P. R. A theory of infrastructure-led development. Journal of Economic Dynamics and Control, v. 34, n. 5, p. 932-950, 2010. Disponível em: https://econpapers.repec.org/article/eeedyncon/v_3a34_3ay_3a2010_3ai_3a5_3ap_3a932-950.htm. Acesso em: 08 jan. 2018.

ASCHAUER, D. A. Is public expenditure productive? Journal of Monetary Economics, v. 23, n. 2, p. 177-200, Mar. 1989. Disponível em: https:/www.sciencedirect.com/science/article/ abs/pii/0304393289900470. Acesso em: 07 jan. 2018.

ATHAYDE, D. R.; VIANNA, A. C. Dívida pública brasileira: uma análise comparativa dos três principais indicadores de esforço fiscal do governo. Nova Economia, v. 25, n. 2, p. 403-420, Ago. 2015.Disponível em: https:/www.scielo.br/j/neco/a/HNvnrJdrfkDzsMyZmhKyTYj/?lan$\mathrm{g}=\mathrm{pt}$. Acesso em: 20 maio 2017.

BANCO CENTRAL DO BRASIL. Relatório Anual 2014. Boletim do Banco Central do Brasil, v. 50, p. 1-230, 2014. Disponível em: https:/www.bcb.gov.br/pec/boletim/banual2014/ rel2014p.pdf. Acesso em: 15 maio 2017.

BARRO, R. J. Cross-country study of growth, saving and government. National Saving and Economic Performance, p. 271-304, Jan. 1991. Disponível em: https://citeseerx.ist.psu.edu/ viewdoc/download?doi=10.1.1.459.7309E $\mathrm{rep}=$ rep1Etype $=$ pdf . Acesso em: 10 ago. 2017.

BEZERRA, A. R.; PEREIRA, R. A. C.; CAMPOS, F. A. O.; CALLADO, M. C. Efeitos de crescimento e bem-estar da recomposição dos investimentos públicos no Brasil. Pesquisa e Planejamento Econômico, v. 44, n. 3, p. 579-607. Dez. 2014. Disponível em: http://repositorio.ipea. gov.br/bitstream/11058/3651/1/PPE_v44_n03_Efeitos.pdf. Acesso em: 28 ago. 2018.

BRASIL. RECEITA FEDERAL. Carga tributária no Brasil 2015: análise por tributo e bases de incidência. Brasília: Secretaria da Receita Federal, 2016.

BREEN, M.; DOYLE, D. The determinants of privatization: a comparative analysis of developing countries, Journal of Comparative Policy Analysis: Research and Practice, v. 15, n. 1, p. 1-20, Dez. 2012. Disponível em: https:/www.tandfonline.com/doi/full/10.1080/13876988.20 13.741439. Acesso em: 20 ago. 2018.

CAMPOS, F. A. O.; PEREIRA, R. A. C. Corrupção e ineficiência no Brasil: Uma análise de equilíbrio geral. Estudos Econômicos, v. 46, n. 2, p. 373-408, 2016. Disponível em: https://www.scielo.br/j/ ee/a/k5MBdyT3NHDT5Y36SsccnjB/?lang=pt . Acesso em: 20 ago. 2018.

CONTROLADORIA GERAL DA UNIÃO. Balanço geral da União. Brasília, 2010. Disponível em: http://www.cgu.gov.br/assuntos/auditoria-e-fiscalizacao . Acesso em: 05 jan. 2017.

CONTROLADORIA GERAL DA UNIÃO. Balanço geral da União. Brasília, 2011. Disponível em: http://www.cgu.gov.br/assuntos/auditoria-e-fiscalizacao . Acesso em: 05 jan. 2017.

CONTROLADORIA GERAL DA UNIÃO. Balanço geral da União. Brasília, 2012. Disponível em: http://www.cgu.gov.br/assuntos/auditoria-e-fiscalizacao. Acesso em: 05 jan. 2017. 
CONTROLADORIA GERAL DA UNIÃO. Balanço geral da União. Brasília, 2013. Disponível em: http://www.cgu.gov.br/assuntos/auditoria-e-fiscalizacao . Acesso em: 05 jan. 2017.

CONTROLADORIA GERAL DA UNIÃO. Balanço geral da União. Brasília, 2014. Disponível em: http://www.cgu.gov.br/assuntos/auditoria-e-fiscalizacao . Acesso em: 05 jan. 2017.

CHIEZA, R. A.; FRANCHESCINI, R.; SANTOS, D. R. Alternativas à redução da regressividade do imposto de renda da pessoa física no Brasil. Análise Econômica, v. 38, n. 76, p. 237-262, jun. 2020. Disponível em: https://www.seer.ufrgs.br/AnaliseEconomica/article/view/82019 . Acesso em: 05 out. 2020.

COELHO, R. O futuro da privatização no Brasil. In: PINHEIRO, A. C.; FUKASAKU, K. A privatização no Brasil: o caso dos serviços de utilidade pública. Rio de Janeiro: BNDES, 370 p., 2000. Disponível em: https://web.bndes.gov.br/bib/jspui/handle/1408/2222. Acesso em: 05 jan. 2017.

COOK, P.; UCHIDA Y. Privatisation and economic growth in developing countries. The Jounal of Development Studies, v. 39, n. 6, p. 121-154, 2003. Disponível em: https://www.tandfonline.com/doi/abs/10.1080/00220380312331293607. Acesso em: 05 out. 2020.

COOLEY, T. F. HANSEN, G. Tax distortion in a neoclassical monetary economy. Journal of Economic Theory, v. 58, n. 2, p. 290-316, Dez. 1992. Disponível em: https://www.sciencedirect.com/science/article/abs/pii/002205319290056N . Acesso em: 06 jan. 2017.

COOLEY, T. F.; PRESCOTT, E. Economic growth and business cycles. In: COOLEY, T.F. (ed.). Frontiers of business cycle research. Nova Jersey: Princeton University, p. 1-38. 1995.

COSTA JÚNIOR, C. J.; FANTINATTI, A. M.; TELES, V. K. A política fiscal expansionista que contrai. Análise Econômica, v. 37, n. 73, p. 225-259, jun. 2019.

FERREIRA, P. C. Essays on public expenditure and economic growth. Unpublished Ph.D. dissertation. University of Pennsylvania, 1993.

FILIPOVIC, A. Impact of privatization on economic growth. Undergraduate Economic Review, v. 2, n 1, 2006. Disponível em: https://digitalcommons.iwu.edu/cgi/viewcontent.cgi?article $=1016$ Econtext $=$ uer . Acesso em: 06 fev. 2017.

GOMES, J.W.F.; PEREIRA, R.A.C.; BEZERRA, A. R. Efeitos distributivos do aumento nos investimentos públicos em infraestrutura no Brasil. Pesquisa e Planejamento Econômico - PPE, v. 49, n. 2, Ago. 2019. Disponível em: https://ppe.ipea.gov.br/index.php/ppe/article/viewFile/1971/1290 . Acesso em: 10 abr. 2020.

HOLLAND, M. Fiscal crisis in Brazil: causes and remedy. Brazilian Journal of Political Economy, v. 39, n. 1, p. 88-107, 2019. Disponível em: https://www.scielo.br/j/rep/a/hGjmC7y3GmcZQ7vhnLhLt5s/?lang=en . Acesso em: 05 abr. 2020.

INSTITUTO BRASILEIRO DE GEOGRAFIA E ESTATÍSTICA. Contas nacionais. Sistema de Contas Nacionais 2010-2014. Rio de Janeiro, 2014.

INSTITUTO BRASILEIRO DE GEOGRAFIA E ESTATISTICA (IBGE). Contas nacionais. Sistema de Contas Nacionais 2017. Rio de Janeiro, 2019. Disponível em: https:/www.ibge.gov.br/ 
estatisticas/economicas/contas-nacionais/9052-sistema-de-contas-nacionais-brasil.html?edi$\mathrm{cao}=25916 \mathcal{E} \mathrm{t}=$ sobre. Acesso em: 06 jan. 2020.

INTERNATIONAL MONETARY FUND. Making public investment more efficient. Staff Report. Washington D.C., Jun. 2015. Disponível em: https://www.imf.org/external/np/pp/ eng/2015/061115.pdf . Acesso em: 2 ago. 2017.

INSTITUTO DE PESQUISA ECONÔMICA APLICADA (IPEADATA). Rio de Janeiro. 2019.

Disponível em: http://www.ipeadata.gov.br Acesso em: 15 dez. 2019.

LUCIO, F. G. C. Ineficiência no Setor Público: uma análise dos efeitos macroeconômicos e de bem-estar. 2017. 51 f. Dissertação (mestrado) - Universidade Federal do Ceará. Faculdade de Economia, Administração, Atuária e Contabilidade. Programa de Pós-Graduação em Economia, 2017. Disponível em: http://www.repositorio.ufc.br/handle/riufc/24123 . Acesso em: 20 ago. 2020.

MODIANO, E. Um balanço da privatização nos anos 90. In: PINHEIRO, A. C. FUKASAKU, K. (Ed.). A privatização no Brasil: o caso dos serviços de utilidade pública. Rio de Janeiro: Banco Nacional de Desenvolvimento Econômico e Social, 2000. 370 p.

MORANDI, L. REIS, E. J. Estoque de capital fixo no Brasil, 1950-2002. Anais do XXXII Encontro Nacional de Economia - ANPEC, Dezembro, João Pessoa, 2004. 20 p. Disponível em: https://core.ac.uk/download/pdf/6357863.pdf . Acesso em: 10 set. 2020.

PARKER, D. KIRKPATRICK, C. Privatisation in developing countries: a review of the evidence and the policy lessons. Journal of Development Studies, v. 41, n. 4, p. 513-541, 2005. Disponível em: https:/www.tandfonline.com/doi/abs/10.1080/00220380500092499. Acesso em: 5 maio 2020.

PEREIRA, R. A. de C.; FERREIRA, P. C. Privatização: uma análise de bem-estar. Estudos Econômicos, v. 48, n.3, p. 391-422, jul.-set. 2018. Disponível em: https://www.scielo.br/j/ee/a/ Ybx3BQgkd5z46XRpzNvgrPm/?format=html. Acesso em: 6 nov. 2019.

PINHEIRO, A. C. Impactos microeconômicos da privatização no Brasil. Pesquisa e Planejamento Econômico, v. 26, n. 3, p. 357-398, Dez. 1996. Disponível em: https://ppe.ipea.gov.br/ index.php/ppe/article/view/744\#: :text =Impactos\%20microeconõmicos\%20da\%20privatização\%20no\%20BrasilËtext=Obtêm-se\%20resultados\%20estatisticamente\%20significativos,alienações\%20realizadas\%20em\%201991\%2F94. Acesso em: 2 dez. 2016.

PINHEIRO, A. C.; GIAMBIAGI, F. Lucratividade, dividendos e investimentos das empresas estatais: uma contribuição para o debate sobre privatização no Brasil. Revista Brasileira de Economia, v. 51, n. 1, p. 93-131, Jan. 1997. Disponível em: https://bibliotecadigital.fgv.br/ojs/ index.php/rbe/article/view/685. Acesso em: 6 fev. 2018.

PLANE, P. Privatization and economic growth: an empirical investigation from a sample of developing market economies. Applied Economics, v. 29, n. 2, p. 161-178, 1997. Disponível em: https:/www.tandfonline.com/doi/abs/10.1080/000368497327245. Acesso em: 20 ago. 2018. 
PRITCHETT, L. The tyranny of concepts: CUDIE (cumulated, depreciated, investment effort) is not capital. Journal of Economic Growth, v. 5, p. 361-384, Dez. 2000. Disponível em: http:// piketty.pse.ens.fr/files/Pritchett00.pdf. Acesso em: 7 set. 2015.

RONDINELLI, D.; IACONO, M. Strategic management of privatization: a framework for planning and implementation. Public Administration and Development, v.16, n. 3, p. 247263, Ago. 1996. Disponível em: https://onlinelibrary.wiley.com/doi/abs/10.1002/\%28SICI\%291099-162X\%28199608\%2916\%3A3<247\%3A\%3AAID-PAD880>3.0.CO\%3B2-O. Acesso em: 25 maio 2017.

SANTANA. P. J.; CAVALCANTI, T. V.; PAES, N. L. Impactos de longo prazo de reformas fiscais sobre a economia brasileira. Revista Brasileira de Economia, v. 66, n. 2, p. 247-269, Jun. 2012.

SHIN, R. W. The paradox of privatization as a public-policy instrument: the case of Korean commercial banks. International Review of Administrative Science, v.56, p. 79-88, 1990. Disponível em: https://journals.sagepub.com/doi/abs/10.1177/002085239005600106. Acesso em: 5 jun. 2015.

SECRETARIA DO TESOURO NACIONAL. Relatório mensal da dívida pública. Dez. 2014. Disponível em: http://www.tesouro.fazenda.gov.br/documents/10180/390360/Texto_RMD_Dezembro_14.pdf/ac00bac2-0fb3-4da5-a596-a8236dd5ff2f. Acesso em: 2 dez. 2016.

\section{Apêndice A}

Tabela 8 - Efeitos de crescimento e bem-estar da política de privatização 1 (dívida)*

\begin{tabular}{lllllllll}
\hline Anos após & $\mathbf{1}$ & $\mathbf{4}$ & $\mathbf{8}$ & $\mathbf{1 2}$ & $\mathbf{2 0}$ & $\mathbf{5 0}$ & $\mathbf{1 0 0}$ & $\mathbf{2 0 0}$ \\
\hline Variáveis & & & & & & & & \\
\hline Consumo privado & 1,0043 & 1,0034 & 1,0027 & 1,0027 & 1,0024 & 1,0020 & 1,0019 & 1,0019 \\
Consumo bens públicos & 1,0000 & 1,0000 & 1,0000 & 0,9961 & 0,9959 & 0,9956 & 0,9955 & 0,9955 \\
Investimento privado & 1,0517 & 1,0523 & 1,0520 & 1,0532 & 1,0533 & 1,0531 & 1,0530 & 1,0530 \\
Salários & 0,9976 & 0,9971 & 0,9966 & 0,9961 & 0,9959 & 0,9956 & 0,9955 & 0,9955 \\
Investimento público & 0,9995 & 0,9983 & 0,9972 & 0,9965 & 0,9961 & 0,9956 & 0,9955 & 0,9955 \\
Produto & 0,9974 & 0,9970 & 0,9965 & 0,9961 & 0,9959 & 0,9956 & 0,9955 & 0,9955 \\
Capital privado & 0,9999 & 0,9995 & 0,9990 & 0,9985 & 0,9977 & 0,9961 & 0,9955 & 0,9955 \\
Dívida pública & 0,9958 & 0,9961 & 0,9962 & 0,9961 & 0,9961 & 0,9962 & 0,9962 & 0,9962 \\
Gastos governo & 0,9970 & 0,9963 & 0,9957 & 0,9955 & 0,9952 & 0,9949 & 0,9948 & 0,9947 \\
\hline
\end{tabular}

Fonte: Elaboração própria.

Notas: Efeito de bem-estar: $x=0,5313 ;{ }^{*}$ destina as receitas obtidas com a privatização para redução da dívida pública. 
Tabela 9 - Efeitos de crescimento e bem-estar da política de privatização 2 (dívida)*

\begin{tabular}{lcccccccc}
\hline Anos após & $\mathbf{1}$ & $\mathbf{4}$ & $\mathbf{8}$ & $\mathbf{1 2}$ & $\mathbf{2 0}$ & $\mathbf{5 0}$ & $\mathbf{1 0 0}$ & $\mathbf{2 0 0}$ \\
\hline Variáveis & & & & & & & & \\
\hline Consumo privado & 0,9984 & 0,9950 & 0,9948 & 0,9979 & 1,0026 & 1,0138 & 1,0179 & 1,0185 \\
Consumo bens públicos & 1,0000 & 1,0000 & 1,0000 & 0,9921 & 0,9973 & 1,0077 & 1,0114 & 1,0119 \\
Investimento privado & 1,0202 & 1,0330 & 1,0424 & 1,0516 & 1,0586 & 1,0673 & 1,0700 & 1,0704 \\
Salários & 0,9882 & 0,9885 & 0,9901 & 0,9921 & 0,9973 & 1,0077 & 1,0114 & 1,0119 \\
Investimento público & 0,9969 & 0,9911 & 0,9885 & 0,9892 & 0,9941 & 1,0066 & 1,0113 & 1,0119 \\
Produto & 0,9882 & 0,9888 & 0,9906 & 0,9928 & 0,9978 & 1,0078 & 1,0114 & 1,0119 \\
Capital privado & 1,0088 & 1,0326 & 1,0595 & 1,0819 & 1,1166 & 1,1798 & 1,2027 & 1,2060 \\
Dívida pública & 0,9797 & 0,9818 & 0,9830 & 0,9832 & 0,9835 & 0,9831 & 0,9829 & 0,9828 \\
Gastos governo & 0,9895 & 0,9878 & 0,9886 & 0,9912 & 0,9961 & 1,0068 & 1,0107 & 1,0112 \\
\hline
\end{tabular}

Fonte: Elaboração própria.

Notas: Efeito de bem-estar: $x=3,4057 ;{ }^{*}$ destina as receitas obtidas com a privatização para redução da dívida pública.

Tabela 10 - Efeitos de crescimento e bem-estar da política de privatização 3 (dívida)*

\begin{tabular}{lcccccccc}
\hline Anos após & $\mathbf{1}$ & $\mathbf{4}$ & $\mathbf{8}$ & $\mathbf{1 2}$ & $\mathbf{2 0}$ & $\mathbf{5 0}$ & $\mathbf{1 0 0}$ & $\mathbf{2 0 0}$ \\
\hline Variáveis & & & & & & & & \\
\hline Consumo privado & 1,0082 & 1,0228 & 1,0341 & 1,0354 & 1,0403 & 1,0450 & 1,0462 & 1,0464 \\
Consumo bens públicos & 1,0000 & 1,0000 & 1,0000 & 1,0377 & 1,0409 & 1,0446 & 1,0458 & 1,0460 \\
Investimento privado & 1,1534 & 1,1426 & 1,1413 & 1,1275 & 1,1251 & 1,1263 & 1,1272 & 1,1273 \\
Salários & 1,0186 & 1,0254 & 1,0320 & 1,0377 & 1,0409 & 1,0446 & 1,0458 & 1,0460 \\
Investimento público & 1,0080 & 1,0262 & 1,0423 & 1,0521 & 1,0584 & 1,0640 & 1,0655 & 1,0657 \\
Produto & 1,0211 & 1,0272 & 1,0336 & 1,0382 & 1,0411 & 1,0447 & 1,0458 & 1,0460 \\
Capital privado & 1,0009 & 1,0041 & 1,0088 & 1,0138 & 1,0224 & 1,0390 & 1,0451 & 1,0460 \\
Dívida pública & 1,0323 & 1,0282 & 1,0259 & 1,0262 & 1,0252 & 1,0247 & 1,0246 & 1,0246 \\
Gastos governo & 0,9084 & 0,9185 & 0,9262 & 0,9292 & 0,9327 & 0,9364 & 0,9375 & 0,9377 \\
\hline
\end{tabular}

Fonte: Elaboração própria.

Nota: Efeito de bem-estar: $x=1,4975$; ${ }^{*}$ destina as receitas obtidas com a privatização para redução da dívida pública. 
Tabela 11 - Efeitos de crescimento e bem-estar da política de privatização 4*

\begin{tabular}{lllllllll}
\hline Anos após & $\mathbf{1}$ & $\mathbf{4}$ & $\mathbf{8}$ & $\mathbf{1 2}$ & $\mathbf{2 0}$ & $\mathbf{5 0}$ & $\mathbf{1 0 0}$ & $\mathbf{2 0 0}$ \\
\hline Variáveis & & & & & & & & \\
\hline Consumo privado & 1,0023 & 1,0147 & 1,0268 & 1,0305 & 1,0408 & 1,0575 & 1,0631 & 1,0639 \\
Consumo bens públicos & 1,0000 & 1,0000 & 1,0000 & 1,0337 & 1,0426 & 1,0576 & 1,0627 & 1,0634 \\
Investimento privado & 1,1224 & 1,1230 & 1,1307 & 1,1264 & 1,1313 & 1,1417 & 1,1456 & 1,1461 \\
Salários & 1,0093 & 1,0169 & 1,0256 & 1,0337 & 1,0426 & 1,0576 & 1,0627 & 1,0634 \\
Investimento público & 1,0054 & 1,0190 & 1,0335 & 1,0445 & 1,0567 & 1,0761 & 1,0825 & 1,0835 \\
Produto & 1,0120 & 1,0192 & 1,0278 & 1,0351 & 1,0435 & 1,0578 & 1,0627 & 1,0634 \\
Capital privado & 1,0100 & 1,0381 & 1,0712 & 1,1002 & 1,1463 & 1,2318 & 1,2628 & 1,2673 \\
Dívida pública & 1,0161 & 1,0140 & 1,0127 & 1,0131 & 1,0123 & 1,0113 & 1,0111 & 1,0110 \\
Gastos governo & 0,9016 & 0,9110 & 0,9201 & 0,9253 & 0,9338 & 0,9479 & 0,9526 & 0,9533 \\
\hline
\end{tabular}

Fonte: Elaboração própria.

Notas: Efeito de bem-estar: $x=4,4470 ;{ }^{*}$ políticas 1 (dívida), 2 (dívida) e 3 (dívida) implementadas de forma simultânea. Destinam as receitas obtidas com a privatização para redução da dívida pública.

\section{Autor correspondente:}

Francisco Germano Carvalho Lucio

E-mail: germano.carvalho@ufca.edu.br
Recebido em: 15/06/2018.

Aceito em: 07/04/2021.

\section{(cc) BY}

Este é um artigo de acesso aberto distribuído sob os termos da Creative Commons Attribution CC-BY 4.0, que permite uso irrestrito, distribuição e reprodução em qualquer meio, desde que o trabalho original seja devidamente citado. 